\title{
Faktor-Faktor yang Mempengaruhi Nyeri Punggung Ibu Hamil Trimester III: Literatur Review
}

\author{
Factors Affecting Back Pain In Pregnant Trimester III : A Literature \\ Review
}

\author{
Melati Nur Arummega ${ }^{1}$, Alfiah Rahmawati ${ }^{2}$, Arum Meiranny ${ }^{3}$ \\ 1,2,3Program Studi Sarjana dan Pendidikan Profesi Bidan Fakultas Kedokteran \\ Universitas Islam Sultan Agung Semarang \\ 1Email : melatisofiya@gmail.com
}

\begin{abstract}
ABSTRAK
Nyeri punggung disebabkan nyeri yang ada di area lumbosakral. Peningkatan intensitasnya seiring pertambahan usia kehamilan diakibatkan dari pergeseran pusat gravitasi serta perubahan pada postur tubuhnya. Nyeri punggung dari sakroiliaka/lumbar bisa menjadi gangguan punggung jangka panjang jika tidak segera dipulihkan. Literatur review ini bertujuan untuk menelaah lebih dalam mengenai nyeri punggung dialami ibu hamil trimester III terdapat faktor yang mempengaruhi dengan cara mereview. Metode literatur review dengan cara mencari di Google Scholar dan PubMed. Kriteria kata kunci yaitu "pregnancy", "back pain", "factors low back pain pregnancy", "aktivitas ibu hamil nyeri punggung”. Setelah dilakukan telaah didapatkan artikel nasional 9 dan internasional 15. Faktor yang mempengaruhi nyeri punggung pada ibu hamil trimester III dapat diklasifikasikan dari usia kehamilan, umur, paritas, aktivitas sehari-hari yang berpengaruh terhadap nyeri punggung dan body relaxation dapat mengurangi rasa nyeri punggung.
\end{abstract}

Kata kunci : Aktivitas Sehari-Hari, Kehamilan Trimester 3, Nyeri Punggung

\section{ABSTRACT}

Back pain is caused by pain in the lumbosacral area. The increase in intensity with increasing gestational age results from a shift in the center of gravity and changes in body posture. Back pain from sacroiliac/lumbar can be a long term back pain if not treated promptly. Literature review aims to examine more deeply about back pain in pregnant women in the third trimester, there were factors that influence it by reviewing. Methods literature review by searching on Google Scholar and PubMed. The keyword criteria are "pregnancy", "back pain", "low back pain pregnancy factors", "back pain pregnant women activities". After the study was conducted, national articles 9 and 15 were obtained. Factors that affect back pain in third trimester pregnant women can be classified from gestational age, age, parity, daily activities that affect back pain and body relaxation can reduce back pain .

Keywords: Daily Activities, 3rd Trimester Of Pregnancy, Back Pain

\section{PENDAHULUAN}

Kehamilan merupakan proses perkembangan pada janin yang dapat menyebabkan ketidaknyamanan akan dialami ibu dan mengakibatkan aktivitas sehari-harinya terganggu (Lailiyana, 2019). Kemenkes RI, 2020 menunjukkan hasil data bahwa banyaknya ibu hamil di Indonesia mencapai sekitar 5.221 .784 orang. Proses kehamilan sendiri melibatkan berbagai perubahan fisiologis diantaranya perubahan fisik, perubahan pada sistem pencernaan, dan sistem respirasi, kemudian sistem traktus 
urinarius, muskuloskeletal serta sirkulasi (L. Fitriani, 2019).

Selama proses adaptasi ibu sering mengalami ketidaknyamanan walaupun fisiologis, namun tetap perlu diberikan suatu pencegahan serta perawatan mengenai beberapa ketidaknyamanan pada Ibu hamil yang memasuki trimester III seperti sakit punggung sekitar $70 \%$ (S. T. R. \& Y. Fitriani, 2019). Menurut penelitian yang dilakukan (Fitriani, 2018), sekitar 70\% dari ibu hamil sering mengalami sakit pada area pinggang atau low back pain (LBP) yang mungkin akan terjadi sejak diawal trimester, dan mengalami puncak saat memasuki trimester II dan III (Wantini, 2021).

Nyeri menjadi suatu masalah sering ditemui selama kehamilan terutama saat memasuki trimester II serta III. Fenomena nyeri menjadi masalah yang kompleks. Definisi menurut International Society for The Study of Pain bahwa "pengalaman sensorik serta emosi tidak menyenangkan yang mengakibatkan kerusakan pada jaringan, baik aktual maupun secara potensial". Nyeri menyebabkan seseorang mengalami ketakutan serta kecemasan sehingga meningkatkan stres dan mengalami perubahan fisiologis secara drastis selama kehamilannya. Nyeri serta kecemasan saling sinergis dan memperburuk antara satu sama lainnya (Purnamasari, 2019).

Namun, masih kebanyakan wanita ada yang merasakan sakit bahkan lebih parah dari biasanya karena terdapat pengaruh dari rasa panik dan stress yang disebut dengan fear-tensionpain concept (takut-tegang-sakit) dapat diartikan bahwa rasa takut mengakibatkan ketegangan atau kepanikan serta menimbulkan otot menjadi lebih kaku dan mengalami rasa sakit (Mardiana, 2021).

Nyeri punggung sering dirasakan di area lumbosakral. Terkadang bisa mengalami peningkatan intensitas bersamaan dengan pertambahan usia kehamilan akibat dari pergeseran pusat gravitasi serta perubahan postur tubuh selama kehamilannya (Sukeksi et al., 2018).

Tanda ketidaknyamanan pada ibu hamil dengan mengalami nyeri di bagian punggung bawah di muskuloskeletal (Glinkowski et al., 2016). Adaptasi muskuloskeletal ini yang perlu diperhatikan dari meningkatnya berat badan, mengalami pergeseran pusat berat tubuh karena 
rahim semakin besar, perlu melakukan relaksasi serta mobilitas. Semakin tinggi instabilitas pada sendi sakroiliaka serta meningkatnya lordosis lumbal menimbulkan rasa sakit. Hal ini mengindikasi bahwa terdapat otot yang mengalami pemendekan saat otot abdomen mulai meregang mengakibatkan ketidakseimbangan pada otot disekitar panggul serta punggung bawah, dan akan terasa di bagian atas ligamen tersebut (Purnamasari, 2019).

Akibat seseorang mengalami nyeri punggung terkadang dari sakroiliaka atau lumbar yang mengakibatkan gangguan di area punggung dan menjadi jangka panjang pada keseimbangan bagian otot serta stabilitas pelvis jika tidak segera dipulihkan setelah melahirkan atau postpartum (Purnamasari, 2019). Risiko Low Back Pain pada kehamilan berikutnya sangat tinggi setelah ada riwayat Low Back Pain pada kehamilan sebelumnya dan konsisten dengan Low Back Pain pada kehamilan sebelumnya (Omoke et al., 2021).

Nyeri punggung terdapat faktorfaktor yang mempengaruhinya seperti usia kehamilan mulai timbul nyeri sesuai dengan penelitian yang dilakukan oleh Katonis et al. biasanya terjadi pada
27 minggu, yang didukung dengan melaporkan 20-28 minggu sebagai periode pertama di mana rasa sakit terjadi (Bryndal et al., 2020). Umur ibu pada umumnya akan mengalami nyeri punggung bawah diantara usia $20-24$ tahun serta akan mencapai puncaknya saat berusia lebih dari 40 tahun (Sukeksi et al., 2018). Pada paritas sering terjadi pada multipara dan grandemultipara yang lebih berisiko karena otot-otot sudah melemah dan menyebabkan otot mengalami kegagalan dalam menopang dibagian uterus atau rahim yang sudah semakin membesar sehingga banyak yang mengalami nyeri punggung (Fithriyah, Rizki Dyah Haninggar, 2020).

Aktivitas sehari-hari dapat mempengaruhi nyeri punggung bawah dan berdampak negatif pada kemampuan ibu hamil untuk melakukan aktivitas sehari-hari seperti perawatan diri, berjalan, duduk dan keterlibatan dalam aktivitas seksual (Manyozo et al., 2019). Body relaxation adanya peningkatan tingkat aktivitas fisik harus bermanfaat terutama bagi wanita yang sedang hamil dapat memeberikan manfaat bagi kesehatan janin, yang berpotensi melalui pemeliharaan fungsi 
vaskular plasenta, akan menjadi hasil dari aktivitas fisik selama kehamilan.

Diluar faktor-faktor tersebut didapatkan bahwa merokok juga mempengaruhi nyeri punggung walaupun tidak terlalu signifikan karena rokok sendiri mengandung nikotin dapat berdampak pada sistem saraf pusat dengan perubahan persepsi nyeri, yang dapat menyebabkan nyeri muskuloskeletal di daerah lain dari tubuh (Garcia et al., 2014).

Penelitian ini bertujuan untuk melakukan studi literature review adalah untuk membuktikan dan menelaah lebih dalam bahwa nyeri punggung dialami ibu hamil pada trimester III terdapat faktor yang mempengaruhinya seperti usia kehamilan, umur, paritas, aktivitas sehari-hari dan body relaxation terdapat kesesuaian dengan penelitian-penelitian sebelumnya dengan cara mereview beberapa penelitian.

\section{METODE PENELITIAN}

Metode yang digunakan pada penulisan artikel ini yaitu Literatur Review dengan cara mencari literature melalui media elektronik menggunakan beberapa databased seperti Google Scholar dan PubMed. Kriteria untuk menemukan kata kunci dalam penelusuran literature yaitu "pregnancy”, "back pain”, "factors low back pain pregnancy", "aktivitas ibu hamil nyeri punggung". Setelah dilakukan telaah artikel didapatkan 9 artikel nasional dan 15 artikel internasional.

\section{HASIL DAN PEMBAHASAN}

Nyeri punggung bagian bawah sering dialami ibu hamil sebagai keluhannya terutama memasuki trimester III karena pusat keseimbangan badan bergeser maju searah dengan tulang belakang dan beban rahim berada di atas daerah pelvis akan menyebabkan pelvis bergeser ke depan sehingga pinggang semakin melengkung (Gozali et al., 2020).

Nyeri bagian punggung bawah lebih banyak dirasakan oleh wanita hamil terutama saat memasuki trimester II serta III dan menjadi keluhan umum yang sering dirasakannya sehingga diperkirakan sekitar $70 \%$ wanita hamil mengeluhkan beberapa bentuk nyeri punggung selama kehamilan, persalinan hingga postpartum (Purnamasari, 2019). Selama kehamilan terjadi relaksasi pada sendi pelvic sehingga mengakibatkan perubahan hormonal dari estrogen, 
progesterone serta relaksin dan akan lebih terlibat. Estrogen sendiri menyebabkan jaringan ikat menjadi lembut, serta kapsula sendi terasa lebih relaks dan sendi pelvis dapat bergerak (Ulfah \& Wirakhmi, 2017).

Postur tubuh pada wanita hamil secara bertahap pasti mengalami perubahan karena janin akan semakin besar didalam abdomen sehingga dapat mengompensasi penambahan berat badan pada ibu hamil, kemudian pada bahu lebih tertarik ke belakang dan tulang lebih melengkung, sedangkan sendi tulang belakang lebih terasa lentur menyebabkan nyeri punggung pada beberapa wanita hamil (Vivian dan Sunarsih, 2011). Gejala-gejala nyeri punggung akan terasa sakit di area punggung atau panggul, kemudian di bagian bokong dan kaki mengakibatkan ibu hamil mengalami sulit dalam berjalan (Sukeksi et al., 2018).

Menurut Sabino dan Grauer yang mencatat bahwa nyeri punggung menjalar ke kaki ke lutut pada kehamilan dan selama periode postpartum merupakan gejala Low Back Pain pada wanita hamil. Para penulis berpendapat bahwa itu disebabkan oleh perubahan yang terjadi di daerah panggul (relaksasi ligamen panggul), sementara nyeri panggul juga memanifestasikan dirinya di bagian distal tungkai bawah (Bryndal et al., 2020). Studi lain yang mengikuti wanita hamil dengan nyeri punggung bawah terdapat faktor yang berkontribusi untuk kelangsungan nyeri: penurunan daya tahan otot, diukur untuk otot ekstensor punggung serta untuk otot abduktor pinggul, dan peningkatan gerakan pada sendi panggul (Ferreira et al., 2021). Nyeri punggung pada ibu hamil dipengaruhi beberapa faktor, antara lain:

a. Usia Kehamilan

Menurut Mogren serta Pohjanen menyatakan bahwa rasa sakit tersebut biasanya terjadi antara 20 dan 28 minggu kehamilan, dengan usia kehamilan rata-rata diperkirakan 22 minggu. Timbulnya nyeri pada penelitian yang dilakukan oleh Katonis et al. biasanya terjadi pada 27 minggu, yang dia dukung dengan melaporkan 20-28 minggu sebagai periode pertama di mana rasa sakit terjadi (Bryndal et al., 2020). Penelitian sebelumnya ditemukan bahwa terdapat tingkat nyeri di area punggung bawah lebih banyak terjadi pada ibu hamil yang mulai 
memasuki trimester III

(Purnamasari, 2019).

Menurut

penelitian

(Glinkowski et al., 2016) bahwa sudut lordosis dan nyeri paling tinggi terjadi pada trimester ketiga kehamilan. Studi oleh McCrory menunjukkan perbedaan fungsional yang signifikan antara wanita hamil, dan wanita yang tidak hamil. Dalam semua studi postur yang dikutip, perubahan terbesar terjadi pada trimester ketiga kehamilan dan disertai dengan gejala nyeri terbesar (Manyozo et al., 2019).

Nyeri punggung pada wanita hamil yang memasuki trimester III dalam melakukan aktivitas fisik yang terlalu banyak dan berlebihan yang biasanya ibu hamil lebih banyak mengurus rumah tangga dan harus bekerja membuat ibu merasa kelelahan dan kurangnya istirahat yang cukup (Fithriyah, Rizki Dyah Haninggar, 2020).

Wanita di trimester kedua (OR 1,83 disesuaikan, $\mathrm{p}=.12$ ) dan trimester ketiga (disesuaikan OR 2.35, $\mathrm{p}=.03$ ) memiliki kemungkinan lebih tinggi mengalami Low Back Pain dibandingkan dengan wanita pada trimester pertama. Hasil ini lebih lanjut setuju dengan temuan dari penelitian lain tentang Low Back Pain pada kehamilan oleh Emilia et al dan Ferreira et al, Low Back Pain sebagai efek dari perubahan pada sistem muskuloskeletal termasuk perubahan postural, peningkatan beban pada tulang belakang karena pertumbuhan janin dan lordosis berlebihan yang mengerahkan kekuatan fisik pada sendi tulang belakang dan menyebabkan disfungsi (Manyozo et al., 2019).

Menurut (Sencan et al., 2018) bahwa wanita dengan Low Back Pain dan nyeri kaki disertai kram mengalami disabilitas sedang menurut skor ODI, dan mereka yang dirawat di trimester ketiga lebih banyak disabilitas dibandingkan mereka yang dirawat di trimester pertama dan kedua. Temuan ini mendukung bahwa kecacatan lebih tinggi pada trimester ketiga daripada trimester lainnya karena kelebihan beban tulang belakang.

Kemampuan fisik menurun pada trimester terakhir kehamilan. Seorang ibu hamil dengan masalah 
punggung bahkan lebih terbatas dalam aktivitasnya. Beberapa penelitian menunjukkan hubungan antara intensitas nyeri yang tinggi dan penurunan kemampuan fungsional (Çoban et al., 2011).

b. Umur Pada umumnya nyeri
punggung bawah akan mulai
dialami pada perempuan yang berusia antara 20 sampai 24 tahun yang akan mencapai puncaknya pada saat usia lebih dari 40 tahun (Sukeksi et al., 2018). Penelitian tersebut sependapat dengan (Mardiana, 2021) bahwa umur serta pendidikan responden yang didapat terlihat dari sebagian besar berada di usia antara 20 - 35 tahun dan pendidikannya sebagian besar SMA sehingga memudahkan dalam menerima informasi yang diberikan.

Pengujian lebih lanjut perlu dilakukan jika lebih banyak komorbiditas di antara wanita yang lebih muda atau distribusi wanita yang menganggur dapat menjelaskan hasil ini, tetapi tidak menemukan perbedaan yang signifikan secara statistik di antara kelompok usia. Oleh karena itu nyeri punggung bawah pada kehamilan harus dipahami dalam konteks yang lebih luas seperti pada pasien dengan nyeri kronis (Backhausen et al., 2019).

c. Paritas

Menurut penelitian bahwa ibu multipara serta grandemultipara akan mengalami nyeri punggung dan lebih berisiko di bandingkan dengan yang primipara karena ototototnya lebih lemah menyebabkan kegagalan pada otot untuk menopang bagian uterus atau rahim semakin membesar. Tanpa adanya sokongan atau penopang, uterus terlihat kendur dan punggung semakin memanjang lengkungannya. Kelemahan pada otot di bagaian abdomen umumnya dialami oleh grandemultipara (Fithriyah, Rizki Dyah Haninggar, 2020).

Menurut penelitian dari Resmi, Dewi Candra dkk, 2017 bahwa terdapat hubungan secara signifikan antara paritas dengan nyeri punggung pada kehamilan. Semakin sering serta banyaknya seseorang wanita yang hamil dan melahirkan, maka risiko lebih besar dibandingkan wanita yang 
primipara. Paritas banyak akan meningkatkan risiko mengalami nyeri punggung. Semakin sering seorang wanita hamil serta melahirkan, maka semakin meningkat risiko nyeri punggung yang dialami (Demang, 2020).

d. Aktivitas Sehari-hari

Pada ibu hamil menunjukkan hasil yang relevan bahwa Low Back Pain intens memiliki prevalensi tinggi dan membawa keterbatasan penting pada aktivitas kehidupan sehari-hari ibu hamil, serta mengidentifikasi wanita yang lebih rentan terhadap kondisi ini. Ini perlu diperhatikan dengan kesehatan profesional untuk menyadari adanya gejala ketidaknyamanan di muskuloskeletal selama kehamilan, terutama nyeri punggung bawah, dan harus mempertimbangkan untuk mengatasi masalah ini terutama selama konsultasi prenatal/ANC rutin (Duarte et al., 2018).

Perubahan patologi dapat ditandai dengan adanya nyeri yang bertambah saat melakukan gerakan (nyeri gerak), dan adanya nyeri penekanan (nyeri tekan), kesalahan sikap misalnya cara duduk, cara berdiri, dan berjalan. Nyeri akan berkurang saat digunakan untuk berbaring (Sukeksi et al., 2018). Penelitian ini sesuai dengan penelitian (Omoke et al., 2021) bahwa beberapa pekerjaan rumah tangga seperti menyapu, mengepel, membersihkan, mengambil dan membawa ember berisi air, membelah dan memasak dengan kayu bakar, mengasuh anak, dan sebagainya, biasanya menekan daerah punggung bawah, dan dengan perubahan beban tubuh dan mekanik selama kehamilan dapat mudah mengendap dan memperburuk Low Back Pain. Tidak ada mekanisme pembagian kerja rumah tangga dan kebutuhan akan salah satunya sering dikaburkan oleh latar belakang budaya peran gender.

Menurut penelitian (Garcia et al., 2014) bahwa bukan suatu kebetulan bahwa prevalensi Low Back Pain yang lebih tinggi diamati dan ditemukan pada sekelompok ibu rumah tangga karena di rumah mereka sendiri di mana perempuan lebih banyak terkena jam kerja yang panjang termasuk merawat 
anak kecil, sering mengangkat dan membawa beban berat, melakukan tugas dalam posisi yang tidak nyaman, dan penggunaan alat yang tidak memadai. Selain itu, pekerjaan ibu rumah tangga mungkin kurang diakui atau dihargai, yang menghasilkan lingkungan menjadi frustrasi dan keadaan emosional yang kompleks.

Nyeri punggung bawah berdampak negatif pada kemampuan ibu hamil untuk melakukan aktivitas sehari-hari seperti perawatan diri, berjalan, duduk dan keterlibatan dalam aktivitas seksual. Keterbatasan fungsional ini juga dikaitkan dengan penurunan kualitas hidup dan penurunan produktivitas di antara wanita hamil. Hasil kami konsisten dengan temuan dari Pakistan, Amerika Serikat dan Brazil di mana wanita juga dilaporkan dengan kualitas hidup yang buruk, aktivitas fungsional harian yang terbatas dan kecacatan terkait karena Low Back Pain terkait kehamilan. Hasil serupa juga dilaporkan oleh Gutke et al yang melaporkan bahwa sekitar $73 \%$ ibu hamil di Norwegia mengalami masalah mobilitas akibat Low Back Pain (Manyozo et al., 2019).

Menurut penelitian dari (Glinkowski et al., 2016) bahwa posisi Lordosis dan kyphosis meningkat secara tidak signifikan dengan kemajuan kehamilan. Berdasarkan hasil didapatkan dengan melihat rasa sakit yang sedikit lebih intens pada pasien dengan perubahan postur yang lebih jelas, tetapi perbedaannya tidak signifikan secara statistik. Hal tersebut menunjukkan peningkatan pengaruh nyeri pada aktivitas sehari-hari pasien seperti berjalan, berdiri, duduk.

Berbagai aktivitas fisik sehari-hari yang sering dilakukan seperti bekerja, aktivitas saat di rumah, ataupun saat waktu luang dengan istirahat, serta berolahraga. Aktivitas lebih berat seperti bekerja serta berolahraga mengakibatkan nyeri pada seseorang (Fithriyah, Rizki Dyah Haninggar, 2020).

Gambaran klinis yang melibatkan nyeri punggung bawah yang parah dan persisten sampai wanita tersebut mengalami kesulitan dalam menggendong bayi dan penurunan tinggi badan yang 
terkait dengan fraktur kerapuhan vertebra. Hal tersebut memiliki dampak negatif pada hubungan antara ibu dan bayi karena pembatasan aktivitas sehari-hari dan rasa sakit yang terkait, dan kondisi ini merupakan penyebab penting kecacatan dalam jangka panjang. Diagnosis dini dan pengobatan kasus ini sangat penting dalam pencegahan patah tulang dan meningkatkan kualitas hidup pasien (Terzi et al., 2014).

Kemampuan fisik ibu hamil dievaluasi dalam enam domain : yaitu, mandi, berpakaian, toileting, transfer, kontinensia dan makan. Ditemukan bahwa semua ibu hamil yang berpartisipasi dalam penelitian mampu melakukan semua kegiatan secara mandiri, dan skor ibu hamil dengan Low Back Pain secara signifikan lebih rendah. Penelitian sebelumnya melaporkan bahwa nyeri punggung berdampak negatif pada kegiatan ibu hamil sehari-hari (Çoban et al., 2011).

\section{e. Body Relaxation}

Peningkatan aktivitas fisik
lebih bermanfaat terutama bagi
wanita hamil. Hal ini karena
memberi manfaat bagi kesehatan

janin melalui pemeliharaan fungsi vaskular plasenta, akan menjadi hasil dari aktivitas fisik selama kehamilan. Meningkatkan harga diri dan kepuasan citra tubuh serta mengurangi terjadinya risiko perkembangan depresi, baik pada tahap postpartum dan antenatal akan dicapai selama kehamilan dengan melakukan latihan fisik (Salwa A. Almalki, Eman F. Ibraheem, 2021). Beberapa dari keluhan ini mereda secara spontan, sedangkan beberapa dapat berkembang menjadi nyeri kronis.

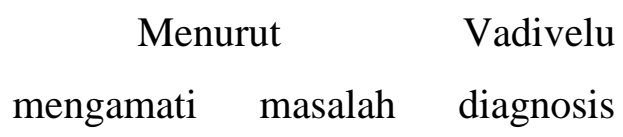
periode postpartum pada wanita yang terus menderita nyeri di tulang belakang lumbosakral yang menjalar ke ekstremitas bawah hingga lutut, yang kemudian tercermin dalam pendekatan medis. Aktivitas fisik pra-kehamilan yang teratur mengurangi terjadinya Low Back Pain selama periode kehamilan, sementara pekerjaan berat meningkatkan risiko Low Back Pain selama kehamilan. Melakukan latihan menstabilkan bermanfaat bagi wanita hamil yang menderita nyeri punggung bawah 
dan panggul sehingga aktivitas fisik selama masa kehamilan dapat mencegah nyeri punggung bawah dan panggul di masa depan terjadi pada kehamilan berikutnya (Bryndal et al., 2020).

Pendapat lain dari (Shiri et al., 2018) bahwa olahraga selama kehamilan mengurangi nyeri punggung bawah dan nyeri korset panggul lebih dari 20\%. Namun, karena kekuatan statistik yang rendah, efek nyeri punggung bawah tidak mencapai signifikansi statistik dan akan berisiko mengalami jika mereka menganggur. Efek perlindungan olahraga terhadap Low Back Pain selama kehamilan masuk akal. Latihan meningkatkan kekuatan dan daya tahan otot dan tampaknya lebih efektif dalam pencegahan episode baru nyeri punggung bawah ketika menjadi kebiasaan.

Prenatal massage bisa menurunkan rasa ketidaknyamanan dan sakit di area punggung selama masa kehamilan, karena mengurangi kelelahan serta tubuh terasa lebih berenergi caranya dengan mengeluarkan hasil metabolisme dalam tubuh limfatik serta sistem sirkulasi. Ketidaknyamanan pada wanita hamil sering dirasakan seperti kram, kemudian ketegangan otot, serta kaku di setiap otot dapat berkurang setelah diberikan pijatan karena membantu sirkulasi menjadi lebih lancar dan mempermudah kerja pada jantung serta tekanan darah sehingga wanita hamil merasa tubuhnya lebih segar. Selain itu, hormon endorphin yang dihasilkan saat pemijatan dapat membantu ibu merasa lebih relax selama kehamilannya (Fithriyah, Rizki Dyah Haninggar, 2020).

Endorphin massage yaitu pengobatan dengan non farmakologis yang dapat meringankan nyeri punggung pada ibu hamil di trimester III. Bidan diharapkan memberikan pelayanan dengan melakukan asuhan kebidanan kepada ibu hamil terutama yang sudah memasuki trimester III dengan keluhan nyeri punggung sehingga dapat diberikan nasihat untuk melakukan teknik endorphin massage agar nyeri punggung lebih berkurang (Gozali et al., 2020). 


Pada wanita hamil yang
melakukan teknik endorphin
massage menurut Beyaz dkk.
terdapat keterbatasan mendasar
pada program latihan aerobik yang
disesuaikan bersama dengan
peregangan, penguatan, relaksasi,
dan latihan pernapasan yang
dilakukan di bawah pengawasan
ahli fisioterapi tetapi mereka hanya
menilai parameter subjektif untuk
menilai tingkat nyeri sebelum dan
sesudah intervensi dan tidak
mengeksplorasi tes fisik yang
digunakan dalam evaluasi klinis

(Ferreira et al., 2021).

Dibandingkan dengan latihan umum, latihan stabilitas inti menjadi lebih efektif mengurangi rasa sakit serta meningkatkan fungsi fisik pada pasien dengan Low Back Pain kronis dalam jangka pendek. Terapi manual dengan berolahraga menunjukkan bahwa menggabungkan berbagai bentuk lebih baik daripada terapi manual (Hu et al., 2020).

Efek olahraga pada Low Back Pain kronis menambah bukti jenis olahraga yang tampak memiliki efek yang sama dan lebih baik daripada yang lain. Sebuah tinjauan Cochrane pada latihan di beberapa gangguan muskuloskeletal kronis menyimpulkan bahwa aktivitas fisik dan olahraga adalah intervensi dengan beberapa efek samping yang dapat meningkatkan rasa sakit dan fungsi fisik, dan akibatnya kualitas hidup. Namun, baru-baru ini, menunjukkan bahwa ada bukti berkualitas rendah bahwa Pilates, latihan ketahanan dan latihan aerobik adalah pengobatan yang paling efektif. Selain itu, menyertakan hasil pada jenis latihan yang kurang dipelajari seperti pelatihan akuatik, berjalan, Latihan Tradisional Cina, dan latihan sling, yang semuanya juga menunjukkan konsistensi dengan hasil sebelumnya bahwa tidak ada jenis latihan yang tampaknya lebih bermanfaat daripada yang lain (Grooten et al., 2021).

Menurut penelitian dari (Lailiyana, 2019) bahwa waktu latihan olahraga pada wanita yang hamil yang baik dengan dianjurkan maksimal selama 30 menit dengan melihat kelelahan sangat berpengaruh pada kehamilan (Megasari, 2015). Back exercise 
dianjurkan untuk melakukannya secara teratur karena dapat membantu sendi serta jaringan di tubuh terasa lebih lentur serta seimbang karena nyeri punggung bawah segera diobati. Lamanya latihannya sekitar 15-60 menit untuk semua jenis. Modulasi yang akan didapatkan dengan mengurangi ekstabalitas reseptor (misalnya pendinginan), kemudian membantu kelancaran metabolisme menyebabkan substansi pada nyeri antara lain bradikinin, prostaglandin, serta histamine berada di fase inaktivasi.

Menurut Khoiruddin (2016), mengenai Kinesio tapping bisa membantu menstabilkan serta menopang bagian struktur pada jaringan lunak ditemukan dalam tubuh seperti otot, tendon, ligamen maupun sendi yang terdapat cedera atau nyeri. Aliran darah serta limfatik diusahakan benar-benar berjalan dengan lancar agar mampu digerakkan secara aktif tanpa adanya nyeri serta mempersingkat proses penyembuhan secara alami dan baik. Kinesio tapping sendiri dapat membantu melebarkan terutama pada sirkulasi dengan membawa $\mathrm{O}_{2}$ ke otot, sehingga berkontraksi secara maksimal. Berdasarkan penelitian juga didapatkan senam hamil menambah keuntungan terutama mempertahankan serta meningkatkan kesehatan secara fisik pada ibu hamil, kemudian memperlancar pada peredaran darah, mengurangi keluhan seperti kram atau pegal-pegal pada tubuh ibu hamil, dan mempersiapkan pernafasan, serta aktivitas bagian otot panggul untuk menghadapi proses persalinan (L. Fitriani, 2019).

Latihan dengan cara memiringkan bagian panggul yang biasa disebut pelvic tilt yaitu latihan yang bisa dan mudah dilakukan di rumah. Latihan ini tidak dianjurkan dengan posisi berbaring supaya menghindari terjadinya supine hiotensive syndrome. Tujuannya dapat memperkuat otot perut, serta otot gluteus maksimus, kemudian memperbaiki postur pada tubuh ibu (mengurangi hiperlordosis) dan mengurangi rasa sakit di area punggung (Ulfah \& Wirakhmi, 2017). 
Melakukan metode seperti pilates sudah banyak dikenal di berbagai Negara dan terbukti mampu mempertahankan kebugaran terutama bagi ibu hamil dan membantu mempermudah selama proses persalinannya. Gerakan-gerakan menggunakan metode ini lebih berpusat pada otototot berguna untuk kebugaran dengan menurunkan rasa nyeri punggung bawah yang bermanfaat saat proses persalinan (Mardiana, 2021).

Yoga hamil juga mampu memberikan keseimbangan bagi tubuh, pikiran dan kepribadian yang berbeda sehingga dianjurkan melakukannya dengan penuh energi, kekuatan dan kejelasan dalam tujuan hidup. Saat wanita sedang hamil dianjurkan melakukan secara rutin sekitar 2-3 kali setiap minggu, supaya membantu menjaga elastisitas dan kekuatan pada ligament panggul, pinggul serta otot di kaki sehingga mengurangi rasa nyeri yang ditimbulkan saat persalinan serta memberikan ruang untuk jalan lahir (L. Fitriani, 2019).
Tingginya prevalensi Low Back Pain yang dilaporkan pada wanita hamil dijelaskan, antara lain, oleh kelebihan beban mekanis yang ditanggung wanita selama kehamilan, perubahan hormonal, redistribusi air tubuh, peningkatan viskositas darah karena defisit fibrinolisis, iskemia relatif struktur tulang belakang, perubahan postur tubuh, dan terjadinya sindrom kompartemen.

Beberapa penjelasan yang dijelaskan dalam literatur menyatakan bahwa merokok menghasilkan perubahan $\mathrm{pH}$ dan perfusi cakram intervertebralis, sementara melemahkan otot paravertebral yang memberikan dukungan pada tulang belakang, yang dapat menyebabkan penurunan resistensi terhadap ketegangan dan proses penyembuhan yang tertunda. Nikotin juga dapat berdampak pada sistem saraf pusat dengan perubahan persepsi nyeri, yang dapat menjelaskan nyeri muskuloskeletal di daerah lain dari tubuh (Garcia et al., 2014). 


\section{SIMPULAN DAN SARAN}

Berdasarkan Literature Review yang sudah dibuat didapatkan faktorfaktor yang mempengaruhi nyeri punggung pada ibu hamil trimester III dapat diklasifikasikan dari usia kehamilan, umur, paritas, aktivitas sehari-hari yang berpengaruh terhadap nyeri punggung dan body relaxation dapat mengurangi rasa nyeri punggung. Didapatkan bahwa ibu yang merokok dapat sementara melemahkan otot paravertebral yang memberikan dukungan pada tulang belakang, sehingga menyebabkan nyeri punggung tetapi hal ini tidak terlalu signifikan.

Saran untuk literature review selanjutnya diharapkan dapat menggunakan databased yang lebih banyak dari artikel internasional maupun artikel dari nasional, kemudian sesuaikan artikel agar relevan dengan judul yang digunakan serta menggunakan artikel yang kurang dari 10 tahun terakhir agar rujukan yang digunakan lebih update atau terbaru.

\section{DAFTAR PUSTAKA}

Backhausen, M. G., Bendix, J. M., Damm, P., Tabor, A., \& Hegaard, H. K. (2019). Low back pain intensity among childbearing women and associated predictors. A cohort study. Women and Birth, 32(4), e467-e476. https://doi.org/10.1016/j.wombi.20 18.09.008

Bryndal, A., Majchrzycki, M., Grochulska, A., Glowinski, S., \& Seremak-mrozikiewicz, A. (2020). Risk factors associated with low back pain among a group of 1510 pregnant women. Journal of Personalized Medicine, 10(2), 110.

https://doi.org/10.3390/jpm100200 51

Çoban, A., Arslan, G. G., Çolakfakioglu, A., \& Sirlan, A. (2011). Impact on quality of life and physical ability of pregnancyrelated back pain in the third trimester of pregnancy. Journal of the Pakistan Medical Association, 61(11), 1122-1124.

Demang, M. G. G. \& F. Y. (2020). Pengaruh Senam Hamil Terhadap Penurunan Nyeri Punggung Bawah Pada Ibu Hamil Trimester II DAN III. Jurnal Kebidanan, 5(2), 56-61. https://doi.org/10.35874/jib.v9i2.5 74

Duarte, V. M., Meucci, R. D., \& Cesar, J. A. (2018). Severe low back pain among pregnant women in Southern Brazil. Ciencia e Saude Coletiva, 23(8), 2487-2494. https://doi.org/10.1590/141381232018238.22562016 
Ferreira, V., Iuamoto, L., \& Hsing, W. (2021). Multidisciplinary management of musculoskeletal pain during pregnancy: A review of literature. The Journal of the International Society of Physical and Rehabilitation Medicine, 4(2), 63. https://doi.org/10.4103/jisprm000099

Fithriyah, Rizki Dyah Haninggar, \& R. S. D. (2020). Pengaruh Prenatal Massage Terhadap Penurunan Nyeri Punggung Pada Ibu Hamil Trimester III (Di Desa Ceweng, Kecamatan Diwek, Kabupaten Jombang). Jurnal Kebidanan, 10(2), 36-43.

Fitriani, L. (2019). Efektivitas Senam Hamil Dan Yoga Hamil Terhadap Penurunan Nyeri Punggung Pada Ibu Hamil Trimester III Di Puskesmas Pekkabata. J-KESMAS: Jurnal Kesehatan Masyarakat, 4(2), 72. https://doi.org/10.35329/jkesmas.v $4 \mathrm{i} 2.246$

Fitriani, S. T. R. \& Y. (2019). Pengaruh Yoga Prenatalterhadap Nyeri Punggung Pada Ibu Hamil Trimester II Dan III Di Lia Azzahra Mom \& Baby Spa Tegal. Indonesia Jurnal Kebidanan, 3(2), 67-72.

Garcia, J. B. S., Hernandez-Castro, J. J., Nunez, R. G., Pazos, M. A. R., Aguirre, J. O., Jreige, A., Delgado, W., Serpentegui, M., Berenguel, M., Cantemir, C., \& Cantisani, A. F. (2014). Prevalence of Low Back Pain in Latin America: Pain Physician, 17(5), 379-391.

Glinkowski, W. M., Tomasik, P., Walesiak, K., Głuszak, M., Krawczak, K., Michoński, J., Czyzewska, A., Zukowska, A.,
Sitnik, R., \& Wielgoś, M. (2016). Posture and low back pain during pregnancy - 3D study. Ginekologia Polska, 87(8), 575-580. https://doi.org/10.5603/GP.2016.00 47

Gozali, W., Astini, N. A. D., \& Permadi, M. R. (2020). Intervensi Nyeri Punggung pada Ibu Hamil di Desa Pengelatan. International Journal of Natural Science and Engineering, 4(3), 134. https://doi.org/10.23887/ijnse.v4i3. 29368

Grooten, W. J., Boström, C., Halvorsen, M., Nilsson-wikmar, L., \& Rasmussen-barr, E. (2021). Summarizing the Effects of Different Exercise Types in Chronic Low Back Pain - A Systematic Review of Systematic Reviews. Research Square, 1-35.

Hu, X., Ma, M., Zhao, X., Sun, W., Liu, Y., Zheng, Z., \& Xu, L. (2020). Effects of exercise therapy for pregnancy-related low back pain and pelvic pain: A protocol for systematic review and metaanalysis. Medicine (United States), 99(3), 1-7. https://doi.org/10.1097/MD.00000 00000017318

Lailiyana, H. \& S. W. (2019). Perbedaan Intensitas Nyeri Punggung Bawah Pada Ibu Hamil Trimester III Yang Dilakukan Back Exercise Dengan Dan Tanpa Kinesio Tapping Di Praktik Mandiri Bidan Dince Safrina Kota Pekanbaru Tahun 2019. 7(1).

Manyozo, S. D., Nesto, T., Bonongwe, P., \& Muula, A. S. (2019). Low back pain during pregnancy: Prevalence, risk factors and association with daily activities 
among pregnant women in urban Blantyre, Malawi. Malawi Medical Journal, 31(1), 71-76. https://doi.org/10.4314/mmj.v31i1. 12

Mardiana, H. R. (2021). Perbedaan Penurunan Skala Nyeri Punggung Pada Ibu Hamil Trimester III Dengan Senam Hamil Dan Tanpa Senam Hamil Di Desa Seduri Kecamatan Mojosari Mojokerto. Jurnal Kesehatan Hesti Wira Sakti, 9(1).

https://doi.org/10.47794/jkhws

Omoke, N. I., Amaraegbulam, P. I., Umeora, O. U. J., \& Okafor, L. C. (2021). Prevalence and risk factors for low back pain during pregnancy among women in Abakaliki, Nigeria. Pan African Medical Journal, 39. https://doi.org/10.11604/pamj.2021 .39.70.24367

Purnamasari, K. D. (2019). Nyeri Punggung Bawah Pada Ibu Hamil Trimester II Dan III. Journal of Midwifery and Public Health, 1(1), 9.

https://doi.org/10.25157/jmph.v1i1 .2000

Salwa A. Almalki, Eman F. Ibraheem, T. A. (2021). Level of exercise and physical activity among pregnant women in Saudi Arabia: A systematic review. Journal of Family Medicine and Primary Care, 10(6), 2140-2147. https://doi.org/10.4103/jfmpc.jfmp c

Sencan, S., Ozcan-Eksi, E. E., Cuce, I., Guzel, S., \& Erdem, B. (2018). Pregnancy-related low back pain in women in Turkey: Prevalence and risk factors. Annals of Physical and
Rehabilitation Medicine, 61(1), 33-37.

https://doi.org/10.1016/j.rehab.201 7.09.005

Shiri, R., Coggon, D., \& Falah-Hassani, K. (2018). Exercise for the prevention of low back and pelvic girdle pain in pregnancy: A metaanalysis of randomized controlled trials. European Journal of Pain (United Kingdom), 22(1), 19-27. https://doi.org/10.1002/ejp.1096

Sukeksi, N. T., Kostania, G., \& Suryani, E. (2018). Pengaruh Teknik Akupressure Terhadap Nyeri Punggung Pada Ibu Hamil Di Wilayah Puskesmas Jogonalan I Klaten. Jurnal Kebidanan Dan Kesehatan Tradisional, 3(1), 1-7. https://doi.org/10.37341/jkkt.v3i1. 61

Terzi, R., Terzi, H., Özer, T., \& Kale, A. (2014). A rare cause of postpartum low back pain: Pregnancy- and lactationassociated osteoporosis. BioMed Research International, 2014, 3-5. https://doi.org/10.1155/2014/28783 2

Ulfah, M., \& Wirakhmi, I. N. (2017). Perbedaan Manfaat Sebelum Dan Sesudah Latihan Pelvic Tilt Terhadap Nyeri Punggung Ibu Hamil Trimester III. Jurnal Ilmiah Ilmu-Ilmu Kesehatan, 15(2), 8083.

Wantini, S. W. \& N. A. (2021). Ketidaknyamanan Fisik dan Psikologis Pada Ibu Hamil Trimester III Di Wilayah Puskesmas Berbah Sleman Daerah Istimewa Yogyakarta. Jurnal Kebidanan Indonesia, 12(1), 5467. 